\title{
Silver Complex of an $N$-Heterocyclic Carbene Ligand with Bulky Thiocarbamate Groups
}

\author{
Elvis Robles-Marín, ${ }^{a}$ Alexander Mondragón, ${ }^{b}$ Marcos Flores-Alamo ${ }^{c}$ and \\ Ivan Castillo ${ }^{*}, a$ \\ ${ }^{a}$ Instituto de Química, Universidad Nacional Autónoma de México, Circuito Exterior, \\ CU, 04510 Ciudad de México, Mexico \\ ${ }^{b}$ Universidad del Valle, Ciudad Universitaria Meléndez, Calle 13 No. 100-00, 76001 Cali, Colombia \\ ${ }^{c}$ Facultad de Química, División de Estudios de Posgrado, Universidad Nacional Autónoma de México, \\ CU, 04510 Ciudad de México, Mexico
}

\begin{abstract}
The synthesis of a new $N$-heterocyclic carbene with bulky $S$-arylthiocarbamate substituents was devised from the condensation between 2-chloromethyl-4-methy-1,6-[3,5-bis(trifluoromethyl)phenyl]-S-phenyl- $N, N$-dimethylthiocarbamate and imidazole, resulting in the proligand $N, N$ '-bis[(2-S-( $N$,,$N$ "-dimethylthiocarbamoyl)-5-methyl)phenylmethyl]imidazolium iodide $\left[\mathrm{H}(\mathrm{S} \text {-carb })_{2} \mathrm{NHC}\right] \mathrm{I}$. This newly synthesized proligand was crystallographically characterized, thus confirming its identity; its stability was established in several solvents, resulting in air oxidation in methanolic solution, giving rise to the decomposition product $N, N^{\prime}$-bis [ $\left(2-S\right.$ - $\left(N N^{\prime \prime}, N\right.$ "'-dimethyl thiocarbamoyl)-5-methyl)phenylmethyl]-4,5-dimethoxyimidazolyl-2-one. Reaction of the proligand with silver oxide afforded the corresponding complex $\left[(S \text {-carb })_{2} \mathrm{NHC}\right] \mathrm{AgI}$, which was fully characterized by spectroscopic techniques.
\end{abstract}

Keywords: carbenes, organic reactions, inorganic synthesis, spectroscopy

\section{Introduction}

$\mathrm{N}$-Heterocyclic carbenes (NHCs) have aroused great interest in recent decades due to their stability and their potential applications in transition metal catalyzed transformations, ${ }^{1-6}$ which has led to the gradual progress in the synthesis of this type of compounds for more advanced chemical transformations. ${ }^{7,8}$ Numerous modifications to the basic structure of the classic imidazol-2-ylidenes have allowed the development of platforms with increased capacity to tune the steric and electronic properties of these ligands, ${ }^{9}$ thereby modulating their properties. In this sense, it has been demonstrated that small modifications to the NHC ligands may lead to drastic changes in their $\sigma$-donor properties, stability, or steric constraints, all of which allow fine-tuning of the properties of the metal center. The most commonly exploited modifications of NHC ligands include ring size, ranging from five to seven atoms, ${ }^{10,11}$ changes to the location of the carbon atom, ${ }^{12}$ and the substituents appended to the nitrogen atoms. Among the modifications

*e-mail: joseivan@unam.mx described above, we considered the latter one for the specific purpose of introducing groups at the imidazole $\mathrm{N}$-positions to access sterically hindered, functionalized substituents. In this context, our main synthetic target is a carbene ligand that may be obtained from imidazole upon introduction of the bulky 2-[3,5-bis(trifluoromethyl) phenyl]-4-methyl-S-phenyl- $N, N$-dimethylthiocarbamate moiety, which has been exploited for the preparation of sterically encumbering thiophenolate ligands (Figure 1). The resulting imidazolium salt should allow access to a bis( $S$-arylthiocarbamate)-NHC, with characteristics desirable for the synthesis of sterically hindered metal complexes.<smiles>Cc1cc(Cn2cc[n+](Cc3cc(C)cc(-c4cc(C(F)(F)F)cc(C(F)(F)F)c4)c3SC(=O)N(C)C)c2)c(SC(=O)N(C)C)c(-c2cc(C(F)(F)F)cc(C(F)(F)F)c2)c1</smiles>

Figure 1. NHC precursor $N, N$ '-bis(2-[ $N$ ", $N$ "-dimethyl-S-thiocarbamoyl]3-[3',5'-bis(trifluoromethyl)phenyl]-5-[methyl]phenylmethyl) imidazolium iodide. 
Among the potential applications of ligands with bulky substituents, the synthesis of biologically inspired metal complexes that activate small molecules such as $\mathrm{CO}_{2}$ and $\mathrm{N}_{2}$ in an analogous fashion to metalloenzymatic active sites is one of the most successfully exploited. As an iconic example of these transformations inspired by the active site of metalloenzymes, Holland and co-workers ${ }^{13}$ developed iron complexes that feature a dithiolate ligand, which provides the metal ions with sulfur and carbon-based donors. This donor set, analogous to that present in the active site of nitrogenase, appears to be necessary for the activation of the $\mathrm{N}_{2}$; the sulfur atoms are provided by two chelating arylthiolate donors with 2,4,6-triisopropylphenyl substituents in the ortho position of the thiolates. The bulky groups offer steric protection to prevent the formation of oligomeric or polymeric iron complexes with bridging thiolates. While there are several examples of iron complexes that activate dinitrogen with B, N, C, and P-based ligands, ${ }^{14-19}$ the example reported by Holland and co-workers ${ }^{13}$ is the only one reported to date that has atoms of sulfur and carbon as coordination sites for the metallic center at the same time. Inspired by the SCS (sulfur-carbon-sulfur) pincer ligand, we undertook the synthesis of the NHC ligand with bulky sulfur-containing groups that is herein reported.

\section{Experimental}

All synthetic manipulations were performed under a dry dinitrogen atmosphere in a glovebox or by Schlenk techniques. Tetrahydrofuran (THF) and $\mathrm{Et}_{2} \mathrm{O}$ were obtained oxygen- and moisture free by distilling from sodium/benzophenone under $\mathrm{N}_{2}$. All other reagents were obtained from commercial suppliers unless otherwise stated; 2-formyl-4-methyl-6-[3,5-bis(trifluoromethyl) phenyl]- $N, N$-dimethyl- $S$-phenylthiocarbamate (A) was prepared as previously described. ${ }^{20} \mathrm{H},{ }^{13} \mathrm{C}$, and ${ }^{19} \mathrm{~F}$ nuclear magnetic resonance (NMR) spectra were recorded with a JEOL Eclipse 300 spectrometer at 300, 75, and $282 \mathrm{MHz}$, respectively, using the residual protiated solvent signal or tetramethylsilane (TMS) as internal references (TMS $\delta=0.00, \mathrm{CHCl}_{3} \delta=7.26 \mathrm{ppm}$ ). Electron ionization mass spectrometry (EI-MS) experiments were performed with a JEOL JMS-AX505HA spectrometer. Positive ion fast atom bombardment mass spectra $\left(\mathrm{FAB}^{+} \mathrm{MS}\right)$ were acquired with a JEOL JMS-SX-102A mass spectrometer operated at an accelerating voltage of $10 \mathrm{keV}$ from a nitrobenzyl alcohol matrix by using xenon atoms at $6 \mathrm{keV}$. Infrared (IR) spectra were recorded on a Bruker Tensor 27 spectrophotometer; melting points were acquired with an Electrothermal apparatus and are uncorrected.

\section{X-ray crystallography}

Crystals of $\mathbf{1}, \mathbf{3}$, and $\mathbf{4}$ mounted on glass fiber were studied with Oxford Diffraction Gemini "A" diffractometer with a CCD (charge-coupled device) area detector $\left(\lambda_{\mathrm{MoK} \alpha}=0.71073 \AA\right.$, monochromator: graphite) equipped with a sealed tube X-ray source. The double pass method of scanning was used to exclude noise. Collected frames were integrated by using an orientation matrix determined from the narrow frame scans. CrysAlisPro and CrysAlis RED software packages were used for data collection and data integration. ${ }^{21}$ Final cell constants were determined by global refinement. Collected data were corrected for absorbance by using analytical numeric absorption correction with a multifaceted crystal model based on expressions upon the Laue symmetry using equivalent reflections. ${ }^{15}$ Structure solution and refinement were carried out with the SHELXS-2014 and SHELXL-2014, ${ }^{22,23}$ WinGX v2014.1 software was used to prepare material for publication. ${ }^{24}$ Full-matrix least-squares refinement was carried out by minimizing $\left(\mathrm{Fo}^{2}-\mathrm{Fc}^{2}\right)^{2}$. All non-hydrogen atoms were refined anisotropically. The $\mathrm{H}$-atom of the hydroxy group of 1 was located in the difference map and refined isotropically with $\mathrm{U}_{\text {iso }}(\mathrm{H})=1.5$, where $\mathrm{U}_{\text {iso }}$ is the isotropic atomic displacement parameter. Those attached to $\mathrm{C}$-atoms were placed in geometrically idealized positions and refined as riding on their parent atoms, with $\mathrm{C}-\mathrm{H}=0.95,1.00 \AA$ and $\mathrm{U}_{\text {iso }}(\mathrm{H})=1.2 \mathrm{U}_{\mathrm{eq}}(\mathrm{C})$ for aromatic methine and methylene groups, $\mathrm{U}_{\text {iso }}(\mathrm{H})=1.5 \mathrm{U}_{\mathrm{eq}}(\mathrm{C})$ for methyl group, where $\mathrm{U}_{\mathrm{eq}}$ is the equivalent isotropic displacement parameter. For the crystallographic data, see Supplementary Information section.

\section{Synthesis of precursors and NHC proligand}

2-Hydroxymethyl-4-methyl-6-[3,5-bis(trifluoromethyl)phenyl]- $N, N$-dimethyl-S-phenylthiocarbamate (1)

2-Formyl-4-methyl-6-[3,5-bis(trifluoromethyl) phenyl]- $N, N$-dimethyl-S-phenylthiocarbamate (A, $3.00 \mathrm{~g}$, $6.89 \mathrm{mmol})$ was dissolved in anhydrous THF $(100 \mathrm{~mL})$ under $\mathrm{N}_{2}$, then solid $\mathrm{NaBH}(\mathrm{OAc})_{3}(2.93 \mathrm{~g}, 13.8 \mathrm{mmol})$ was added, affording an off-white suspension; this mixture was heated to reflux for 3 days. After cooling down to room temperature, disappearance of $\mathbf{A}$ was confirmed by thin layer chromatography (TLC, hexane/ ethyl acetate 5:1) together with conversion to one major product. The resulting mixture was filtered through Celite, and the solvent was removed with a rotary evaporator. Subsequently, the solid was filtered through a short plug of silica gel to remove inorganic impurities, using a 1:1 hexane/ethyl acetate solvent mixture to afford $2.86 \mathrm{~g}$ of 1 (95\%). m.p. 103-104 ${ }^{\circ} \mathrm{C}$; ${ }^{1} \mathrm{H}$ NMR (300 MHz, $\mathrm{CDCl}_{3}$ ) 
$\delta 7.86(\mathrm{~s}, 1 \mathrm{H}), 7.75(\mathrm{~s}, 2 \mathrm{H}), 7.52(\mathrm{~s}, 1 \mathrm{H}), 7.19(\mathrm{~s}, 1 \mathrm{H}), 4.78$ (s, 2H), 3.19 (t, J $5.7 \mathrm{~Hz}, 1 \mathrm{H}), 2.98$ (s, 3H), 2.92 (s, 3H), 2.44 (s, 3H); ${ }^{13} \mathrm{C} \mathrm{NMR}\left(75 \mathrm{MHz}, \mathrm{CDCl}_{3}\right) \delta 167.87,147.10$, 145.18, 143.83, 141.48, 131.67, 131.59, 131.23, 130.79, $130.73,130.35,129.80,129.76,128.92,125.31,122.78$, $121.70,121.05,118.09,64.94,37.31,37.15,21.37 ; \mathrm{FAB}^{+}$ MS (rel. int.): $m / z 437$ (40) [M] $]^{+}, 72$ (100) $\left[\mathrm{OCMe}_{2}\right]^{+}$.

$N, N$ '-Bis (2-[N", N"'-dimethyl-S-thiocarbamoyl]3-[3',5'-bis(trifluoromethyl)phenyl]-5-[methyl]phenylmethyl) imidazolium iodide (3)

In a $100 \mathrm{~mL}$ round bottom Schlenk flask under $\mathrm{N}_{2}$ atmosphere imidazole ( $35.6 \mathrm{mg}, 0.52 \mathrm{mmol})$ was dissolved in anhydrous THF, then solid $\mathrm{NaH}(12.5 \mathrm{mg}, 0.52 \mathrm{mmol})$ was added, and the mixture was stirred for $10 \mathrm{~min}$. Then compound $2(0.50 \mathrm{~g}, 1.01 \mathrm{mmol})$ was added together with $\mathrm{NaI}(0.16 \mathrm{~g}, 1.01 \mathrm{mmol})$. The mixture was stirred vigorously for a few minutes, turning pale yellow and slowly becoming cloudy; the reaction was then heated to reflux for 2 days, then cooled down to room temperature for TLC analysis to corroborate complete consumption of 2. The mixture was filtered through Celite, and evaporated under reduced pressure; the solid obtained was extracted with water and dichloromethane. The organic phase was evaporated resulting in a colorless solid, which was washed with diethyl ether $(3 \times 10 \mathrm{~mL})$ and hexane; solid 3 was dried under vacuum affording an $89 \%$ yield $(0.48 \mathrm{~g})$. Single crystals were obtained by slow evaporation of a concentrated dichloromethane (DCM) solution. m.p. 279-281 ${ }^{\circ} \mathrm{C} ; \mathrm{Rf}=0.3$ (hexane/ethyl acetate 1:3); ${ }^{1} \mathrm{H}$ NMR $\left(300 \mathrm{MHz}, \mathrm{CDCl}_{3}\right.$ ) $\delta 10.29(\mathrm{~s}, 1 \mathrm{H}), 7.81$ (s, 2H), 7.67 (s, 4H), 7.59 (s, 2H), 7.37 (d, J $1.3 \mathrm{~Hz}, 2 \mathrm{H}), 7.20\left(\mathrm{~s}, 2 \mathrm{H}\right.$, overlapped $\left.\mathrm{CDCl}_{3}\right), 5.72(\mathrm{~s}$, 4H), $2.83(\mathrm{~d}, J 5.3 \mathrm{~Hz}, 12 \mathrm{H}), 2.38(\mathrm{~s}, 6 \mathrm{H}) ;{ }^{13} \mathrm{C}\left\{{ }^{1} \mathrm{H}\right\} \mathrm{NMR}$ $\left(75 \mathrm{MHz}, \mathrm{CDCl}_{3}\right) \delta 165.65,146.07,143.05,142.32,139.02$, $137.59,132.30$ (d, J $17.3 \mathrm{~Hz}), 131.73,131.29,130.85,130.40$, 129.50, 125.09, 124.58, 122.40, 121.30 (dt, J7.9 Hz), 52.03, 37.22 (d, $J 34.6 \mathrm{~Hz}), 21.22 ;{ }^{19} \mathrm{~F}$ NMR (282 MHz, $\mathrm{CDCl}_{3}$ ) $\delta-62.87 ;{ }^{13} \mathrm{C}$ distortionless enhancement by polarization transfer (DEPT)-135 NMR (75 MHz, $\left.\mathrm{CDCl}_{3}\right) \delta 137.59$, $132.42,132.19,129.46,122.40,121.30$ (dt, $J 7.9 \mathrm{~Hz}), 52.02$ (negative phase), $37.22(\mathrm{~d}, J 34.6 \mathrm{~Hz}), 21.22 ; \mathrm{FAB}^{+} \mathrm{MS}$ (rel. int.): $m / z 907$ (86) [M] ${ }^{+}, 72$ (100) $\left[\mathrm{OCMe}_{2}\right]^{+} ; \mathrm{IR}(\mathrm{KBr})$ $v_{\max } / \mathrm{cm}^{-1} 3453$ (vw), 3101 (vw), 2930 (vw), $1652(\mathrm{~m}), 1563$ (vw), 1378 (w), 1285 (vs), 1165 (m), 1121 (vs). Anal. calcd. for $\mathrm{C}_{41} \mathrm{H}_{35} \mathrm{~F}_{12} \mathrm{IN}_{4} \mathrm{O}_{2} \mathrm{~S}_{2}$ : C, 47.59; H, 3.41; N, 5.41; S, 6.20. Found: C, 48.06; H, 3.20; N, 5.28; S, 6.21.

$N, N$ '-Bis(2-[N", N'"-dimethyl-S-thiocarbamoyl]3-[3',5'-bis(trifluoromethyl)phenyl]-5-[methyl]phenylmethyl)4,5-dimethoxyimidazolyl-2-one (4)

Compound $3(0.12 \mathrm{~g}, 0.13 \mathrm{mmol})$ was placed in $5 \mathrm{~mL}$ of anhydrous $\mathrm{MeOH}$ in a $15 \mathrm{~mL}$ Erlenmeyer flask, and after 4 days yellow crystals were obtained. m.p. $>220^{\circ} \mathrm{C}$ (dec. 117-118 ${ }^{\circ} \mathrm{C}$ ); IR (KBr) $v_{\max } / \mathrm{cm}^{-1} 3437$ (vw), 3131 (vw), 3102 (vw), 2991 (vw), 2931 (vw), 1719 (w), 1658 (m), 1464 (m), 1379 (m), 1284 (vs), 1174 (m), 1126 (vs); FAB ${ }^{+}$MS: $\mathrm{m} / \mathrm{z} 984$ (10) $[\mathrm{M}]^{+} ;{ }^{1} \mathrm{H}$ NMR (300 MHz, TMS) $\delta 7.85$ (s, 2H), 7.79 (s, 4H), 7.38 (s, 2H), 7.20 (s, 2H), 6.30 (s, 2H), $5.08(\mathrm{~s}, 4 \mathrm{H}), 3.27$ (s, 6H), $2.92(\mathrm{~s}, 12 \mathrm{H}), 2.41(\mathrm{~s}, 6 \mathrm{H})$.

\section{Synthesis of complex}

\section{Synthesis of silver carbene complex (5)}

In a $100 \mathrm{~mL}$ round-bottomed Schlenk flask equipped with a Teflon cap under $\mathrm{N}_{2}$ at room temperature, compound $3(0.26 \mathrm{~g}, 0.24 \mathrm{mmol})$ was dissolved in a 7:3 anhydrous ethanol/DCM (dichloromethane) mixture (50 mL), then $\mathrm{Ag}_{2} \mathrm{O}$ (34 mg, $0.15 \mathrm{mmol}$ ) was added; the mixture was stirred vigorously for $15 \mathrm{~min}$, and then heated at $70{ }^{\circ} \mathrm{C}$ for 4 days. The reaction mixture was cooled to room temperature and $\mathrm{NaI}(36 \mathrm{mg}, 0.24 \mathrm{mmol})$ was added, the mixture was further stirred for $2 \mathrm{~h}$. The resulting mixture was filtered through Celite to remove unreacted $\mathrm{Ag}_{2} \mathrm{O}$ and $\mathrm{NaI}$; the filtrate was dried to obtain a colorless solid that was protected from light to avoid photodecomposition. Yield: $93 \%$ yield; m.p. $>250{ }^{\circ} \mathrm{C}$ (dec. 208-209 $\left.{ }^{\circ} \mathrm{C}\right) ; \mathrm{Rf}=0.7(\mathrm{DCM} / \mathrm{MeOH} 9: 1) ;{ }^{1} \mathrm{H}$ NMR $\left(300 \mathrm{MHz}, \mathrm{CDCl}_{3}\right) \delta 7.78$ (s, 2H), 7.69 (s, 4H), 7.21 (s, 2H, overlapped with $\mathrm{CDCl}_{3}$ ), $7.10(\mathrm{~s}, 2 \mathrm{H}), 6.29$ (s, 2H), 5.55 (s, 4H), $2.83(\mathrm{~s}, 12 \mathrm{H}), 2.30(\mathrm{~s}, 6 \mathrm{H}) ;{ }^{13} \mathrm{C} \mathrm{NMR}$ (75 MHz, $\left.\mathrm{CDCl}_{3}\right) \delta 185.54,165.70,145.77,143.53,142.35$, 141.48, 131.27 (d, $J 12.5 \mathrm{~Hz}), 130.82(\mathrm{~d}, J 11.5 \mathrm{~Hz})$, 129.76, 128.89, 125.28, 123.88, 121.95, 121.67, 121.14, 54.08, 37.06 (d, J 31.2 Hz), 21.48; ${ }^{19} \mathrm{~F}$ NMR (282 MHz, $\left.\mathrm{CDCl}_{3}\right) \delta-62.85 ;{ }^{13} \mathrm{C}$ DEPT-135 NMR $\left(75 \mathrm{MHz}, \mathrm{CDCl}_{3}\right)$ $\delta 131.36,130.75,129.69,121.84,121.07,54.08$ (negative phase), 37.20 (d, J 34.6 Hz), 30.54, 21.39; IR (KBr) $v_{\max } / \mathrm{cm}^{-1} 3402$ (vw), 3104 (vw), 2929 (vw), 1651 (m), 1595 (vw), 1376 (w), 1283 (vs), 1169 (m), 1123 (vs); $\mathrm{FAB}^{+} \mathrm{MS}$ :

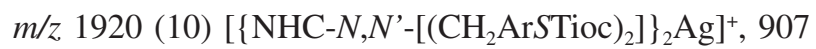
(30) $\left[\mathrm{NHC}-\mathrm{N}, N^{\prime}-\left(\mathrm{CH}_{2} \mathrm{ArSTioc}\right)_{2} \mathrm{Ag}\right]^{+}, 72$ (100) $\left[\mathrm{OCMe}_{2}\right]^{+}$. Anal. calcd. for $\mathrm{C}_{41} \mathrm{H}_{34} \mathrm{AgF}_{12} \mathrm{IN}_{4} \mathrm{O}_{2} \mathrm{~S}_{2}: \mathrm{C}, 43.14 ; \mathrm{H}, 3.00 ; \mathrm{N}$, 4.91; S, 5.62. Found: C, 43.68; H, 3.23; N, 4.74; S, 5.75.

\section{Results and Discussion}

The synthesis of the imidazolium proligand started with 2-formyl-4-methyl-6-[3,5-bis(trifluoromethyl) phenyl]- $N, N$-dimethyl- $S$-phenylthiocarbamate (A), which was reduced to the corresponding benzylic alcohol with $\mathrm{NaBH}(\mathrm{OAc})_{3}$. The procedure was carried out under inert atmosphere in anhydrous THF over a period of 3 days, 
resulting in excellent yields of 2-hydroxymethyl-4-methyl6-[3',5'-bis(trifluoromethyl)-phenyl]- $N, N$-dimethyl$S$-phenylthiocarbamate (1 in Scheme 1). Characterization of the colorless solid is consistent with the proposed formulation: the ${ }^{1} \mathrm{H}$ NMR spectrum of $\mathbf{1}$ showed a singlet at $2.41 \mathrm{ppm}$ that integrates to $3 \mathrm{H}$, and was assigned to the methyl group in the para position of the $S$-arylthiocarbamate (Supplementary Information (SI), Figure S1). The two singlets detected at 2.92 and $2.98 \mathrm{ppm}$ corresponding to $6 \mathrm{H}$ was attributed to the $N$-methyl groups of the $S$-thiocarbamate moiety; this signal is normally observed as a singlet, but restricted rotation about the $\mathrm{C}(\mathrm{O})-\mathrm{N}$ bond may occur if there is hydrogen bonding of the thiocarbamate group with the ortho- $\mathrm{CH}_{2} \mathrm{OH}$ substituent. The signal around $3.19 \mathrm{ppm}(J=5.7 \mathrm{~Hz})$ corresponding to the $\mathrm{OH}$ group appears as a triplet due to resolved coupling to the adjacent methylene protons; it was also possible to observe a singlet at $4.76 \mathrm{ppm}$ that integrates for $2 \mathrm{H}$ that corresponds to the methylene $-\mathrm{CH}_{2} \mathrm{OH}$ protons, although coupling is not resolved for this resonance. Finally, the signals in the aromatic region from 7.17 to $7.83 \mathrm{ppm}$ integrate to $5 \mathrm{H}$, which is consistent with the number of expected protons for $\mathbf{1}$.

Additional characterization by $\mathrm{FAB}^{+}$mass spectrometry evidenced the presence of a peak at $\mathrm{m} / \mathrm{z} 438$, assigned to $[\mathrm{M}+\mathrm{H}]^{+}$with a relative intensity of $30 \%$, as well as a peak at $m / z 420$, which corresponds to the $[\mathrm{M}-\mathrm{OH}]^{+}$species; finally, the presence of the peak at $\mathrm{m} / \mathrm{z} 72$ is of importance since it evidences fragmentation of the thiocarbamate moiety by loss of $\left[\mathrm{O}=\mathrm{CNMe}_{2}\right]^{+}$(see Figure S2, SI section). X-ray quality crystals of $\mathbf{1}$ were obtained by slow evaporation of a 4:1 $\mathrm{CHCl}_{3} / \mathrm{MeOH}$ mixture, thus confirming its identity unequivocally. Table 1 contains the crystallographic data, while Figure 2 shows a Mercury representation of the solid-state structure of $\mathbf{1}$. The most representative bond distances include the carbonyl C17-O1 distance of 1.228(4)

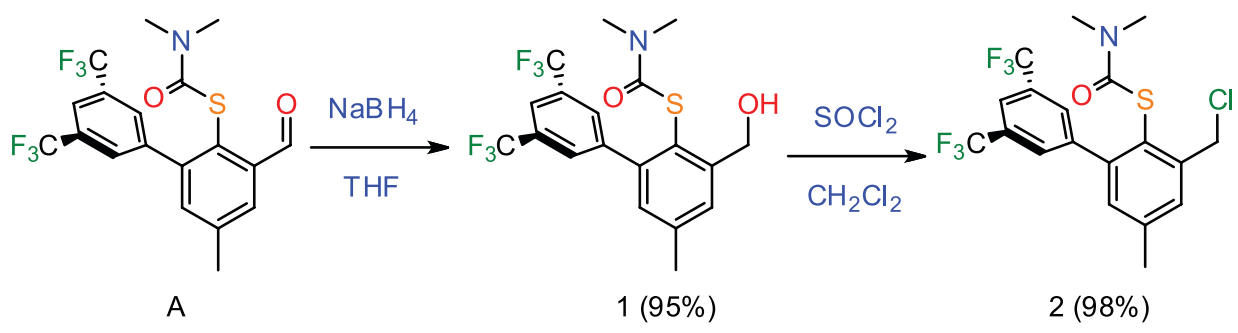

Scheme 1. Synthesis of 2-chloromethyl-S-arylthiocarbamate (2) from A.

Table 1. Selected crystallographic data for $\mathbf{1}, \mathbf{3}$, and $\mathbf{4}$

\begin{tabular}{|c|c|c|c|}
\hline & 1 & 3 & 4 \\
\hline Empirical formula & $\mathrm{C}_{19} \mathrm{H}_{17} \mathrm{~F}_{6} \mathrm{NO}_{2} \mathrm{~S}$ & $\mathrm{C}_{41} \mathrm{H}_{35} \mathrm{~F}_{12} \mathrm{IN}_{4} \mathrm{O}_{2} \mathrm{~S}_{2}$ & $\mathrm{C}_{44} \mathrm{H}_{44} \mathrm{~F}_{12} \mathrm{~N}_{4} \mathrm{O}_{6} \mathrm{~S}_{2}$ \\
\hline Formula weight & 437.4 & 1034.8 & 1016.95 \\
\hline Temperature / K & $130(2)$ & $130(2)$ & $130(2)$ \\
\hline Wavelength / ̊̊ & 0.71073 & 0.71073 & 0.71073 \\
\hline Crystal system & triclinic & monoclinic & triclinic \\
\hline Space group & $P-1$ & $P 2{ }_{1} / \mathrm{c}$ & $P-1$ \\
\hline$a / \AA$ & $5.134(2)$ & $38.551(2)$ & $8.6705(12)$ \\
\hline$b / \AA$ & $10.620(4)$ & $5.1209(2)$ & $12.6456(13)$ \\
\hline$c / \AA$ & $17.878(4)$ & $22.0176(10)$ & $22.103(2)$ \\
\hline$\alpha /$ degree & $99.45(2)$ & 90 & $97.743(8)$ \\
\hline$\beta /$ degree & $96.43(3)$ & $90.316(5)$ & $100.116(10)$ \\
\hline$\gamma /$ degree & $93.37(3)$ & 90 & $100.020(10)$ \\
\hline Volume / $\AA^{3}$ & $952.6(6)$ & $4346.6(3)$ & $2315.0(5)$ \\
\hline $\mathrm{Z}$ & 2 & 4 & 2 \\
\hline$\rho_{\text {calc }} /\left(\mathrm{g} \mathrm{cm}^{-3}\right)$ & 1.525 & 1.581 & 1.459 \\
\hline$\mu / \mathrm{mm}^{-1}$ & 0.242 & 0.925 & 0.215 \\
\hline $\mathrm{F}(000)$ & 448 & 2072 & 1048 \\
\hline $2 \theta$ range for data collection & $3.49-25.03$ & $3.663-25.349$ & $3.389-25.350$ \\
\hline $\mathrm{R}_{\text {int }}$ & 0.0469 & 0.1367 & 0.0332 \\
\hline GOF & 1.059 & 1.122 & 1.326 \\
\hline $\mathrm{R}_{1}[\mathrm{I} \geq 2 \sigma(\mathrm{I})]$ & 0.0583 & 0.0963 & 0.1001 \\
\hline $\mathrm{wR}_{2}[\mathrm{I} \geq 2 \sigma(\mathrm{I})]$ & 0.1281 & 0.1832 & 0.2620 \\
\hline
\end{tabular}

GOF: goodness of fit. 


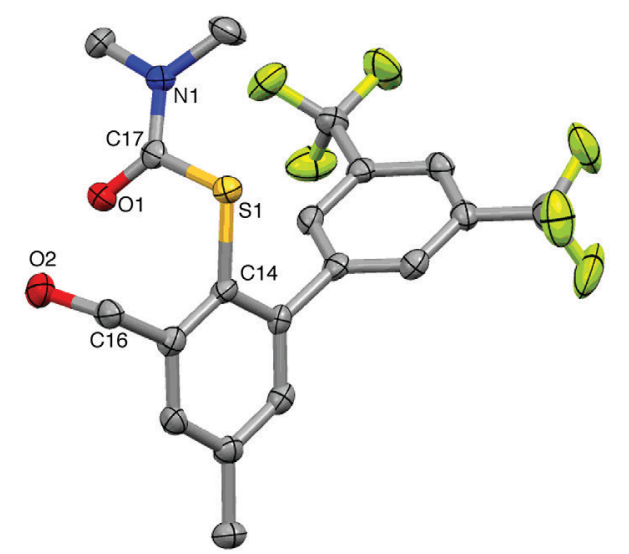

Figure 2. Mercury diagram of $\mathbf{1}$ at the 50\% probability level; H-atoms omitted for clarity. Color code: C, grey; F, green; S, yellow; N, blue; O, red.

of the thiocarbamoyl group, and the considerably longer single bond C16-O2 distance of 1.432(4) $\AA$ of the benzylic alcohol moiety; the aromatic C14-S1 distance of 1.787(4) $\AA$ is slightly shorter than the thiocarbamoyl C17-S1 distance of 1.811(4) $\AA$, while the corresponding C17-N1 bond length is $1.346(4) \AA$. All bond angles are comparable to those of related compounds, including the ones around the thiocarbamate group: O1-C17-N1 123.5(3) ${ }^{\circ}$, O1-C17-S1 121.2(3) ${ }^{\circ}$, and N1-C17-S1 115.3(3) ${ }^{\circ}$. Full crystallographic data are presented in the Supplementary Information, Table S1, and complete bonding parameters are presented in Table S2.
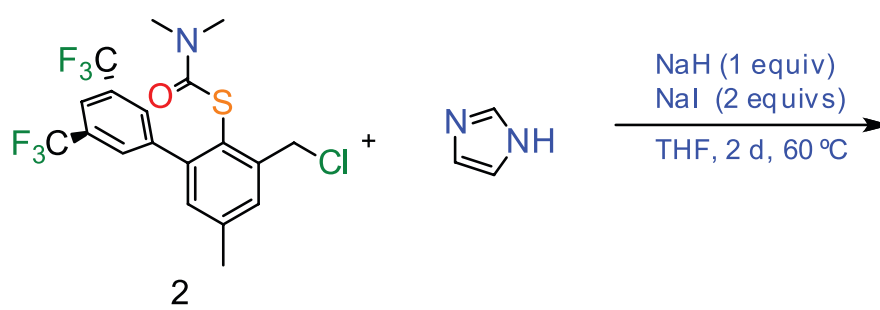

(2 equivs)
The second stage for the preparation of the NHC proligand consisted of the conversion of the previously obtained benzylic alcohol to the corresponding chloride. This procedure required inert atmosphere conditions and anhydrous DCM, as well as an excess of $\mathrm{SOCl}_{2}$. Characterization of 2-chloromethyl-4-methyl6-[3',5'-bis(trifluoromethyl)phenyl]- $N, N$-dimethyl$S$-phenylthiocarbamate (2) was initially carried out by comparison of its ${ }^{1} \mathrm{H}$ NMR spectrum (Figure S3, SI section) with that of its precursor $\mathbf{1}$. Thus, the characteristic signals were identified at $2.37 \mathrm{ppm}$, which is a singlet corresponding to $3 \mathrm{H}$ of the methyl group in the para position. The singlet at $2.84 \mathrm{ppm}$ is consistent with 6 protons of the methyl groups of the $S$-thiocarbamate moiety, which differs from the two resonances observed for the $N, N$-dimethyl fragment in 1; this behavior is attributed to the lack of hydrogen bonding between the hydroxyl group and the thiocarbamate moiety, which results in free rotation about the $\mathrm{C}-\mathrm{N}$ bond. The resonance at $3.96 \mathrm{ppm}$ was assigned to the methylene protons. Finally, four signals were observed in the aromatic region of the spectrum, consistent with the structure of $\mathbf{2}$.

The synthesis of $N, N^{\prime}$-bis (2-[N", $N$ ''-dimethyl$S$-thiocarbamoyl]-3-[3',5'-bis(trifluoromethyl)phenyl]5 -[methyl]phenylmethyl)imidazolium iodide ( 3 in Scheme 2) starts by dissolving imidazole in approximately $50 \mathrm{~mL}$ of anhydrous THF in a Schlenk flask under $\mathrm{N}_{2}$ atmosphere, followed by deprotonation with an equimolar

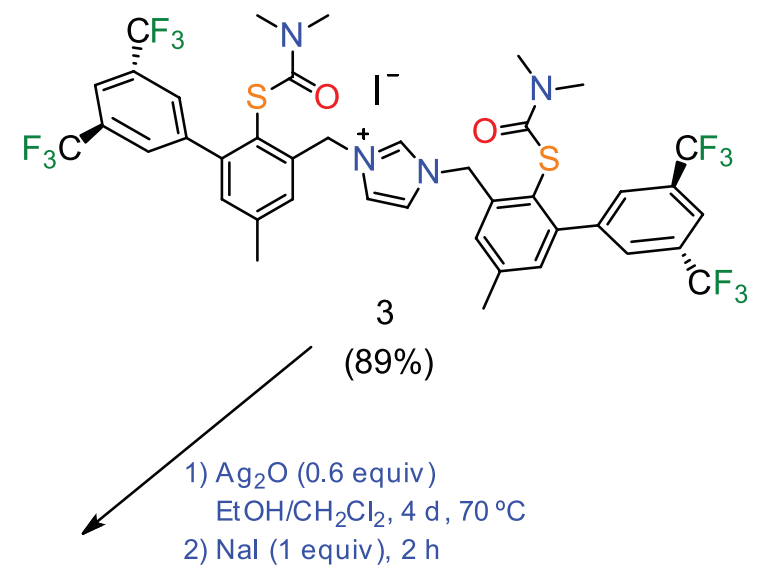

$5(93 \%)$

Scheme 2. Synthesis of proligand $\mathbf{3}$ and the corresponding complex $\mathbf{5}$. 
amount of $\mathrm{NaH}$, which resulted in a turbid reaction mixture. Two equivalents of the benzylic chloride 2 were then added, followed immediately by addition of NaI. After adding all the components of the reaction, the mixture was heated for 2 days until complete consumption of $\mathbf{2}$ was verified by TLC analysis, and the appearance of a colorless precipitate (likely $\mathrm{NaCl}$ ) was evident. It was noticed that employment of excess $\mathrm{NaH}$ was detrimental to the reaction, resulting in a complex mixture since the carbene formed could attack the carbamate moities, forming undesired byproducts.

Initial characterization of $\mathbf{3}$ by ${ }^{1} \mathrm{H}$ NMR spectroscopy revealed a low field signal at $10.29 \mathrm{ppm}$, evidencing the presence of a highly deshielded proton on the imidazole $\mathrm{C} 2$, see Figure 3. Other important resonances are observed at high field, centered at $\delta 2.82$ corresponding to the methyl groups of the tiocarbamate moieties, and at $2.38 \mathrm{ppm}$ corresponding the methyl groups in the aromatic para positions, respectively. It should be noted that the signals at 2.83 and $2.81 \mathrm{ppm}$ are two singlets that correspond to the methyl groups of the thiocarbamate moiety; their inequivalent nature is likely due to the lack of rotational freedom that may be attributed to the proximity of the large iodide counterion, this phenomenon will be addressed in more detail in the structural elucidation by X-ray crystallography. The singlet peak at $5.72 \mathrm{ppm}$ corresponds to $4 \mathrm{H}$ arising from the two methylene bridges that connect the arylthiocarbamate moieties with the imidazole nitrogen atoms, indicating that they are chemically equivalent. Finally, five signals are present in the aromatic region, with the one at lower field (7.81 ppm) attributed to the aromatic protons between the two trifluoromethyl groups in the aromatic ring adjacent to the $S$-arylthiocarbamate, while the singlet at $7.67 \mathrm{ppm}$ corresponds to the protons between the trifluoromethyl groups and the thiocarbamate-containing aromatic group. The pair of doublets at 7.60 and $7.37 \mathrm{ppm}$ $(J=1.2 \mathrm{~Hz})$ is attributed to protons at the arylthiocarbamate meta positions, while the two imidazole protons at the 4- and 5-positions give rise to the singlet observed at $7.20 \mathrm{ppm}$.

In the ${ }^{13} \mathrm{C}$ NMR spectrum (Figure S4, SI section), a total of 22 signals are evidenced, consistent with the structure of 3 . Among the most representative ones are the carbonyl $\mathrm{C}$-atom at $165.7 \mathrm{ppm}$, and the imidazole-based $\mathrm{C} 4$ and $\mathrm{C} 5$ at $132.3 \mathrm{ppm} .{ }^{13} \mathrm{C}$ DEPT-135 helped the assignment, with the negative phase signal at $52.0 \mathrm{ppm}$ arising from the methylene bridge between the imidazole and arylthiocarbamate groups; the two signals centered around 37.2 correspond to the $N$-methyl groups, and the signal at 21.2 to the aromatic para-methyl C-atom (Figure S5, SI section). The aromatic signals cannot be assigned unequivocally with the available data. Nonetheless, the ${ }^{19} \mathrm{~F}$ spectrum (Figure S6, SI section) exhibits a single resonance at $-62.9 \mathrm{ppm}$, consistent with the presence of equivalent trifluoromethyl substituents.

Further characterization of 3 by $\mathrm{FAB}^{+}$mass spectrometry revealed the molecular ion at $m / z 907$, with a relative intensity of $86 \%$. The species detected at $m / z 72$ was described above and ascribed to $\left[\mathrm{O}=\mathrm{CNMe}_{2}\right]^{+}$, which is always present due to fragmentation of the thiocarbamate group; the full spectrum is presented in Figure S7 (SI section), along with the most representative fragments. IR spectroscopic analysis allowed the assignment of peaks corresponding to aromatic and

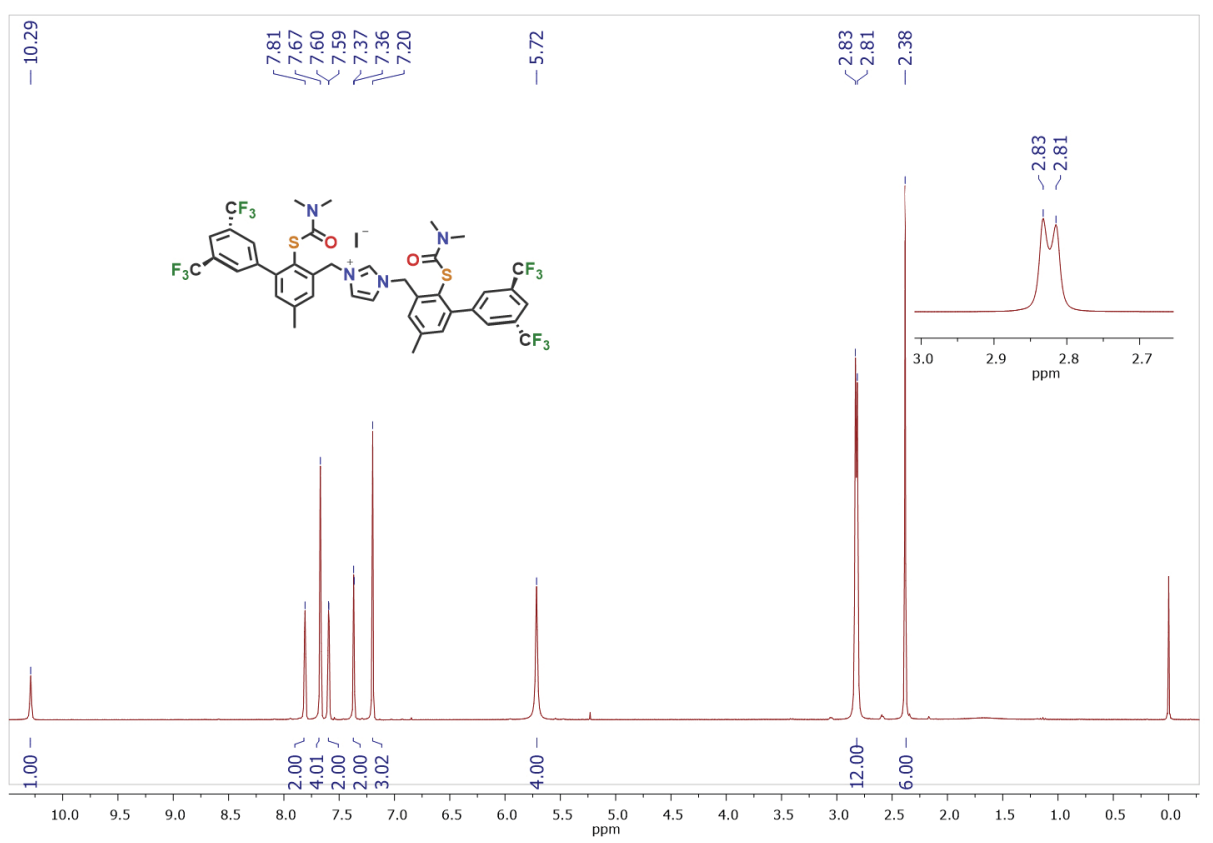

Figure 3. ${ }^{1} \mathrm{H}$ NMR spectrum $\left(300 \mathrm{MHz}, \mathrm{CDCl}_{3}\right.$ ) of proligand 3 at room temperature (inset: $N$-Me signals). 
aliphatic C-H stretches at 3101 and $2930 \mathrm{~cm}^{-1}$, respectively (Figure S8, SI section). Another representative band was observed at $1652 \mathrm{~cm}^{-1}$, corresponding to the carbonyl $\mathrm{C}=\mathrm{O}$ stretching mode of the thiocarbamate moieties.

Suitable crystals of compound $\mathbf{3}$ for X-ray crystallography were obtained by slow evaporation of a concentrated DCM solution, allowing for the solid-state structure elucidation (see Figure 4 and Table 1). Selected bond distances include those of the imidazole ring, N1-C3 1.346(10) and N2-C3 1.331(9) $\AA$, with an N2-C3-N1 angle of $107.8(7)^{\circ}$; the former $\mathrm{N}-\mathrm{C}$ distance would correspond to the formally single bond, and thus $\mathrm{N} 2$ would have to be considered as cationic. The metric parameters of the thiocarbamate moieties are similar to those reported for related compounds, ${ }^{26,27}$ including S1-C20 and S2-C39 of the thiocarbamate groups at 1.820(9) and 1.814(8) $\AA$, respectively; the corresponding carbonyl $\mathrm{O} 1-\mathrm{C} 20$ and O2-C39 distances of 1.113(18) and 1.221(9) $\AA$ are also similar to those observed for related systems. Complete metric parameters are presented in Table S4 (SI section). Further crystallographic analysis of the molecules of $\mathbf{3}$ packed in the unit cell revealed the interactions of the iodide ion with the rest of the molecule, displaying $\mathrm{C}-\mathrm{H} \cdots \mathrm{I}$ bonding interactions. All other bond lengths and angles are within known parameters, and are therefore unexceptional.

In addition to the bonding parameters, the intermolecular interactions of the iodide ions were established, as well as a potential explanation of its effect on the number of signals observed by ${ }^{1} \mathrm{H}$ NMR spectroscopy assigned to the $N$-methyl substituents of the thiocarbamate groups. The latter phenomenon was mentioned previously in the spectroscopic characterization of $\mathbf{3}$. In Figure 5, the crystal packing of $\mathbf{3}$ clearly shows that the iodide anions are involved in several weak $\mathrm{H}$-bonding interactions with $\mathrm{C}-\mathrm{H}$ moieties, including those of one of the thiocarbamate $N$-Me groups at $4.045 \AA$. This interaction may lead to hindered rotation of the $\mathrm{C}-\mathrm{N}$ bonds in solution, giving rise to chemical inequivalent methyl groups.

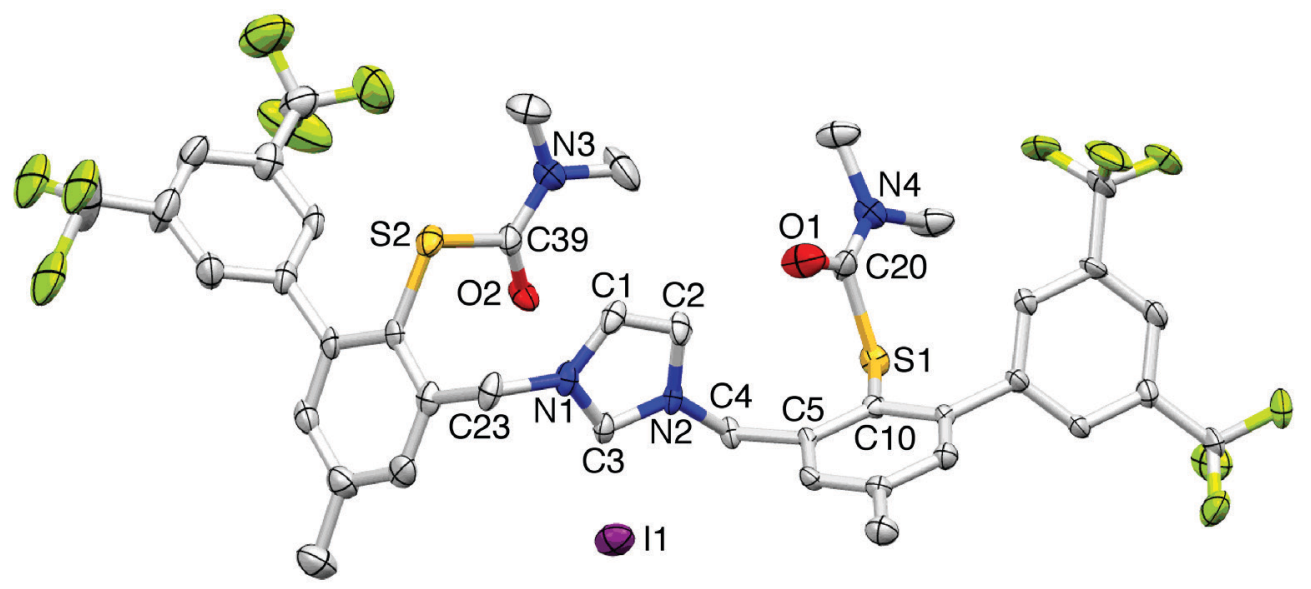

Figure 4. Mercury diagram of $\mathbf{3}$ at the 50\% probability level; H-atoms omitted for clarity. Color code: I, violet.

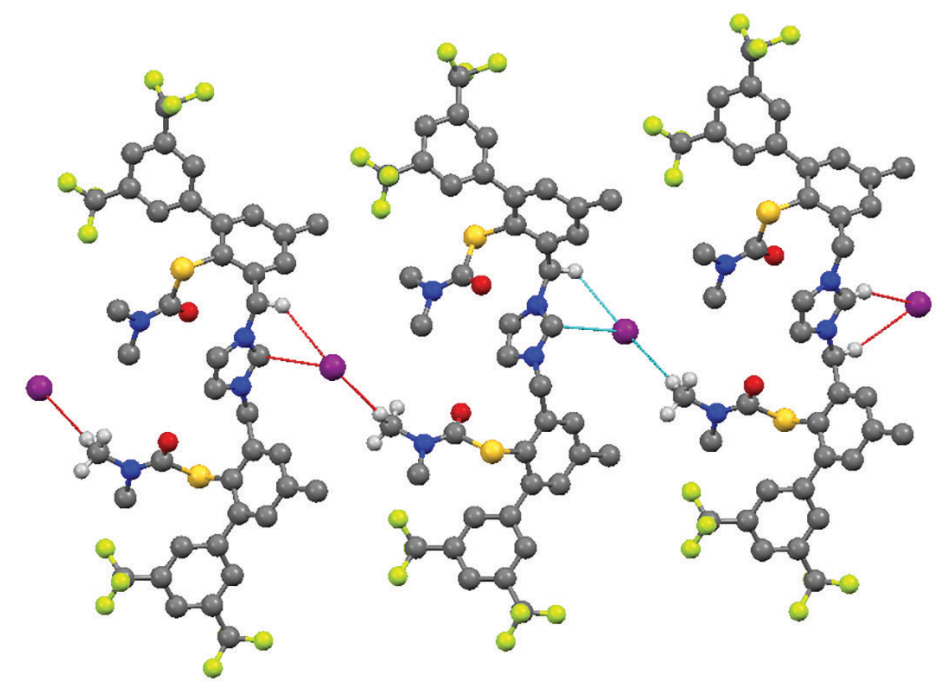

Figure 5. Mercury diagram of an array of $\mathbf{3}$, with iodides forming extended H-bonding interactions with C-H groups, including thiocarbamate $N$-Me groups. 
Crystallization of $\mathbf{3}$ was attempted in different solvents, including acetonitrile, ethanol, chloroform and methanol. It was discovered that in the latter solvent, the colorless crystals obtained correspond to a decomposition product, that we can only speculate was formed by initial air oxidation at the central imidazole $\mathrm{C}$-atom, followed by methanol attack at positions 4 and 5 . The overall transformation resulted in the observed methoxy substituents at such positions of the five-membered ring that can be best described as a cyclic urea derivative. Although the crystals obtained were not of very high quality, the connectivity of the atoms of $N, N$ '-bis (2-[N", $N$ "'-dimethyl$S$-thiocarbamoyl]-3-[3',5'-bis(trifluoromethyl)phenyl]5-[methyl]phenylmethyl)-4,5-dimethoxyimidazolyl2-one (4) was firmly established (see Figure 6).

Once 3 as NHC precursor had been obtained, we decided to use $\mathrm{Ag}_{2} \mathrm{O}$ as silver source for the preparation of the corresponding silver carbene complex by deprotonation of the imidazolium salt, based on the success with which it has been employed. ${ }^{28} \mathrm{An}$ example of this process is represented by the treatment of $N, N^{\prime}$-diethylbenzimidazolium with $\mathrm{Ag}_{2} \mathrm{O}$, which afford mono- or bis(NHC)silver complexes, depending on the identity of the counterion $\left(\mathrm{Br}^{-}\right.$or $\mathrm{PF}_{6}^{-}$, respectively). Moreover, silver complexes serve as excellent NHC transfer agents towards different transition metals. ${ }^{29}$ Thus, the imidazolium proligand $\mathbf{3}$ was dissolved in anhydrous DCM, followed by addition of $\mathrm{Ag}_{2} \mathrm{O}$. The basic oxo ligand must deprotonate the central imidazolium $\mathrm{C}$-atom, leading to formation of the corresponding carbene ligand, which subsequently reacts with the $\mathrm{Ag}^{+}$ions. The $N, N^{\prime}$-bis (2-[N", $N$ "-dimethyl$S$-thiocarbamoyl]-3-[3',5'-bis(trifluoromethyl)phenyl]5 -[methyl]phenylmethyl)imidazolyl silver complex $\left[(S \text {-carb })_{2} \mathrm{NHC}\right] \mathrm{AgI}(\mathbf{5})$ was thus obtained in excellent yield. This procedure was carried out under a nitrogen atmosphere to avoid hydrolysis or oxidation during the reaction. Additionally, the reaction vessel was covered with aluminum foil to avoid the potential light-induced decomposition of silver complexes.

Spectroscopic characterization of $\mathbf{5}$ was undertaken by ${ }^{1} \mathrm{H},{ }^{13} \mathrm{C},{ }^{19} \mathrm{~F}$ NMR, and IR spectroscopy, as well as $\mathrm{FAB}^{+}$ mass spectrometry. Comparison of the ${ }^{1} \mathrm{H}$ NMR spectrum of $\mathbf{5}$ with that of $\mathbf{3}$ reveals the loss of the proton from the 2-position of the imidazole ring of the proligand observed at $10.29 \mathrm{ppm}$ (see Figure 7). Another important difference corresponds to the methyl groups of the carbamate moiety, which appeared as two singlets at 2.83 and $2.81 \mathrm{ppm}$, and converge to a single resonance in $\mathbf{5}$; on the other hand, the rest of the signals shift towards high field, which may be rationalized based on the neutral nature of the ligand, relative to its cationic character in proligand $\mathbf{3}$. In the ${ }^{13} \mathrm{C}$ NMR spectrum (Figure S9, SI section), all the signals expected to complex $\mathbf{5}$ are evidenced; among the most important ones, that of the carbonyl C-atom of the thiocarbamate groups appears at $165.7 \mathrm{ppm}$, while the carbene $\mathrm{C}$-atom bound to the $\mathrm{Ag}^{+}$ion appears at even lower field at $185.5 \mathrm{ppm}$. The DEPT-135 NMR spectrum in Figure S10 (SI section) aided to assign the signal at $54.1 \mathrm{ppm}$ as that arising from the methylene C-atoms $\left(\mathrm{CH}_{2}\right)$ that bridge the thiocarbamate groups and the imidazole ring; the two resonances around $37.2 \mathrm{ppm}$ were assigned to the methyl C-atoms of the $\mathrm{N}$-Me groups, and the peak at $21.5 \mathrm{ppm}$ was attributed to the para-arylthiocarbamate methyl group.

Mass spectrometry analysis shows conclusive evidence of the synthesis of the silver complex $\mathbf{5}$, with a peak observed at $\mathrm{m} / \mathrm{z}, 1013$ corresponding to the molecular ion $\left(\left[(S \text {-carb })_{2} \mathrm{NHC}\right] \mathrm{Ag}\right)^{+}$; comparison of the experimental and calculated isotopic patterns is consistent with the assignment. Another interesting peak was observed at $\mathrm{m} / \mathrm{z}$ 1919, which corresponds to the species formed by two molecules of $\left[(\mathrm{S} \text {-carb })_{2} \mathrm{NHC}\right]$ coordinated to a single $\mathrm{Ag}^{+}$ion

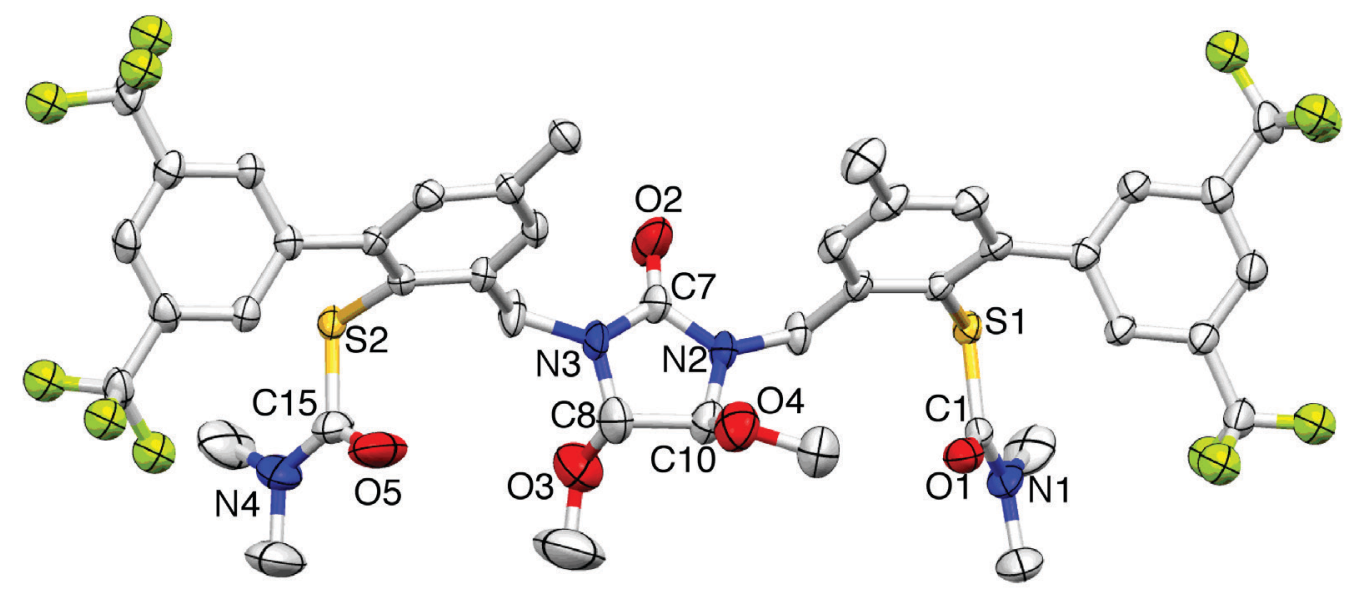

Figure 6. Mercury diagram of $\mathbf{4}$ at the $50 \%$ probability level; $\mathrm{H}$ and minor-occupancy disordered atoms, as well as molecules of methanol omitted for clarity. 


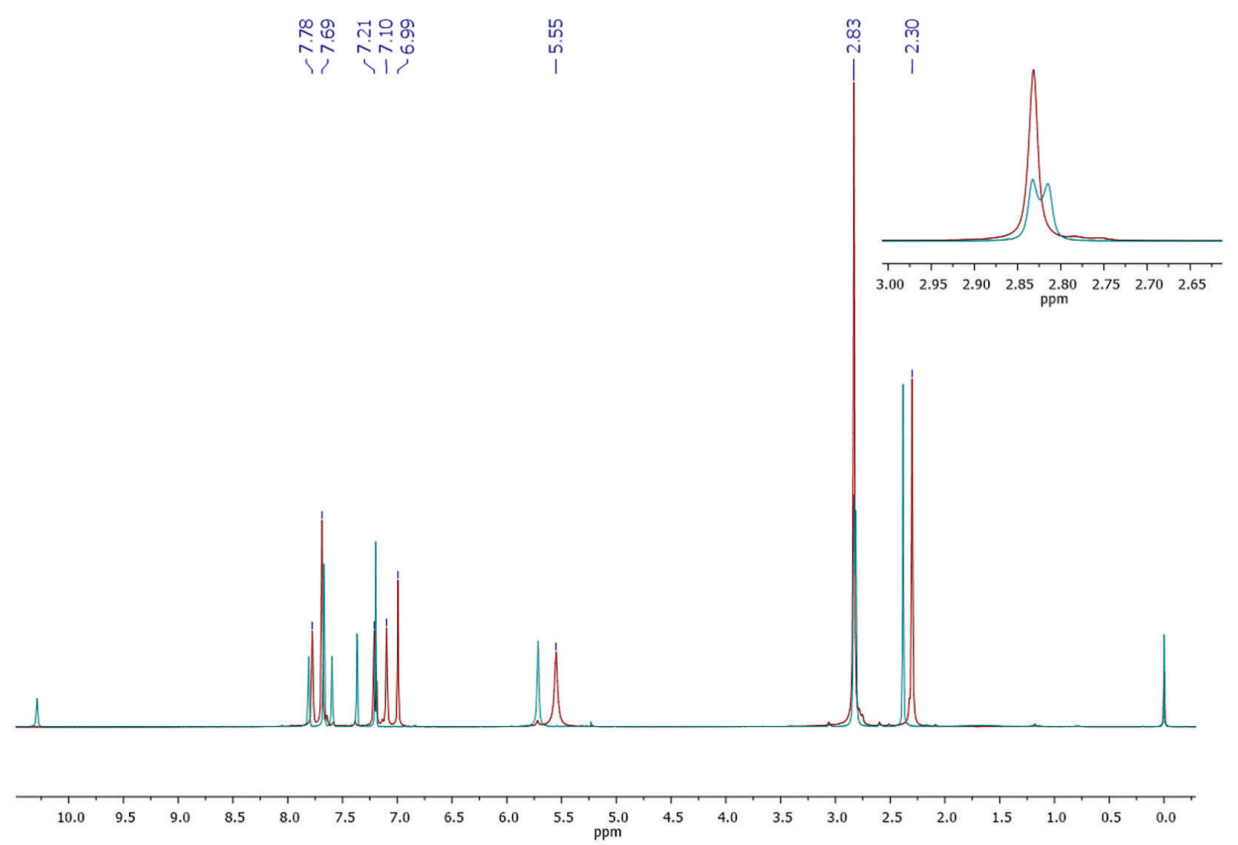

Figure 7. Comparison of ${ }^{1} \mathrm{H}$ NMR spectra (300 $\mathrm{MHz}, \mathrm{CDCl}_{3}$ ) of compounds $\mathbf{3}$ (green), and $\mathbf{5}$ (red) at room temperature.

(Figure 8); this species was not expected due to the presence of bulky groups at the $\mathrm{NHC} \mathrm{N}$-atoms, but it may be formed in situ in the ionization chamber during the $\mathrm{FAB}^{+} \mathrm{MS}$ experiment. It is important to note that the $S$-thioacarbamate groups have free rotation around the S-CO bonds, allowing the formation of $\left[\left\{(S \text {-carb })_{2} \mathrm{NHC}\right\}_{2} \mathrm{Ag}\right]^{+}$, likely due to this conformational flexibility; this may be precluded by chelate formation upon thiocarbamate cleavage and concomitant $\mathrm{M}-\mathrm{S}$ bond formation. Finally, the peak at $\mathrm{m} / \mathrm{z} 907$ corresponds to protonated $\left[\mathrm{H}(S \text {-carb })_{2} \mathrm{NHC}\right]^{+}$, and the other peaks present are attributed to ligand fragmentation, similar to those observed for 3 . Combustion analysis of 5

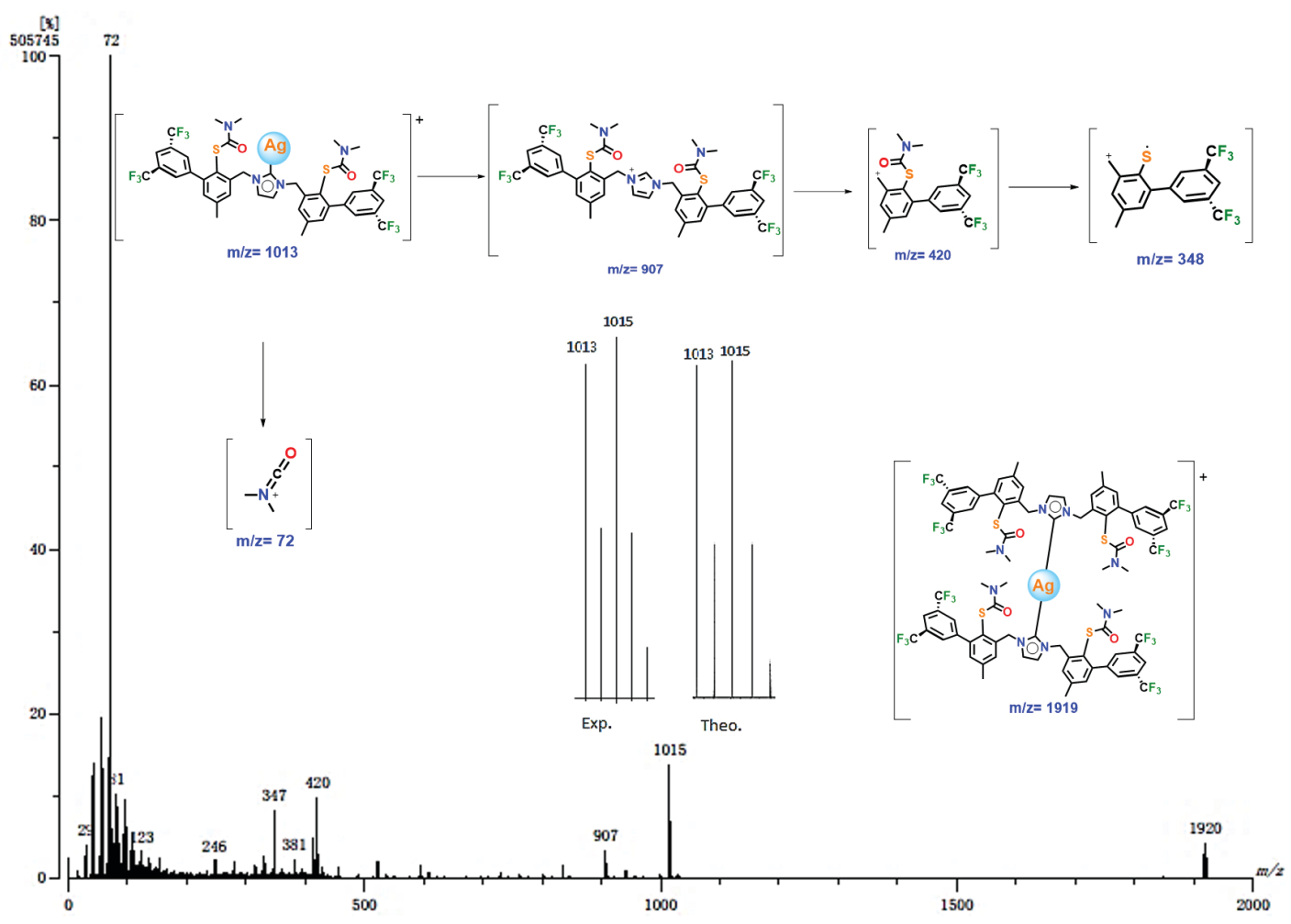

Figure 8. $\mathrm{FAB}^{+} \mathrm{MS}$ of $\mathbf{5}$ and its most important fragments. 
is consistent with the formulation as a complex of silver iodide $\left[(S \text {-carb })_{2} \mathrm{NHC}\right] \mathrm{AgI}$, as shown in Scheme 2.

\section{Conclusions}

In the present work, we have synthesized with excellent yields a new $N$-heterocyclic carbene with $S$-arylthiocarbamate substituents, which was conceived from the condensation between a benzylic chloride precursor and imidazole, resulting in the proligand $\left[\mathrm{H}(S \text {-carb })_{2} \mathrm{NHC}\right] \mathrm{I}(\mathbf{3})$. The newly synthesized compound was characterized by several spectroscopic techniques, and finally by X-ray crystallography. The reaction of 3 with silver oxide resulted in the corresponding silver carbene complex $\left[(S \text {-carb })_{2} \mathrm{NHC}\right] \mathrm{AgI}(5)$, which was characterized spectroscopically. It was discovered that the proligand $\mathbf{3}$ underwent decomposition when exposed to oxygen in methanolic solution, resulting in oxidation at the 2-position of the imidazole ring, which appears to lead to the subsequent attack at positions 4 and 5 by two solvent molecules, generating the crystallographically characterized $N, N$ '-bis[(2-S-( $N$ ", $N$ "'-dimethylthiocarbamoyl)-5-methyl) phenylmethyl]-4,5-dimethoxyimidazolyl-2-one (4).

\section{Supplementary Information}

Crystallographic data have been deposited at the Cambridge Crystallographic Data Centre as supplementary material number CCDC 1588153-1588155. Copies of the data can be obtained free of charge via http://www.ccdc. cam.ac.uk/conts/retrieving.html, or from CCDC, 12 Union Road, Cambridge CB2 1EZ, UK; e-mail: deposit@ccdc. cam.ac.uk.

Supplementary data are available free of charge at http://jbcs.sbq.org.br as PDF file.

\section{Acknowledgments}

The authors thank DGAPA-PAPIIT (IN210214 and IN203317), and Conacyt (Beca 289037) for financial support, Universidad del Valle (convocatoria para el fortalecimiento de visibilidad internacional); María de la Paz Orta for combustion analysis, Rocío Patiño for IR spectroscopy, and Luis Velasco for $\mathrm{FAB}^{+} \mathrm{MS}$.

\section{References}

1. Arduengo, A. J.; Acc. Chem. Res. 1999, 32, 913.

2. Moerdyk, J. P.; Bielawski, C. W. In Contemporary Carbene Chemistry; Moss, R. A.; Doyle, M. P., eds.; John Wiley \& Sons: Hoboken, USA, 2013, p. 40.
3. de Frémont, P.; Marion, N.; Nolan, S. P.; Coord. Chem. Rev. 2009, 253, 862.

4. Nelson, D. J.; Nolan, S. P.; Chem. Soc. Rev. 2013, 42, 6723.

5. Vougioukalakis, G. C.; Grubbs, R. H.; Chem. Rev. 2010, 110, 1746.

6. Hopkinson, M. N.; Richter, C.; Schedler, M.; Glorius, F.; Nature 2014, 510, 485.

7. Fogg, D. E.; dos Santos, E. N.; Coord. Chem. Rev. 2004, 248, 2365.

8. Janssen-Müller, D.; Schlepphorst, C.; Glorius, F.; Chem. Soc. Rev. 2017, 46, 4845.

9. Dröge, T.; Glorius, F.; Angew. Chem., Int. Ed. 2010, 49, 6940.

10. Iglesias, M.; Beetstra, D. J.; Stasch, A.; Horton, P. N.; Hursthouse, M. B.; Coles, S. J.; Cavell, K. J.; Dervisi, A.; Fallis, I. A.; Organometallics 2007, 26, 4800.

11. Scarborough, C. C.; Guzei, I. A.; Stahl, S. S.; Dalton Trans. 2009, 2284.

12. Crabtree, R. H.; Coord. Chem. Rev. 2013, 257, 755.

13. Čorić, I.; Mercado, B. Q.; Bill, E.; Vinyard, D. J.; Holland, P. L.; Nature 2015, 526, 96.

14. Ung, G.; Peters, J. C.; Angew. Chem., Int. Ed. 2015, 54, 532.

15. Rodriguez, M. M.; Bill, E.; Brennessel, W. W.; Holland, P. L.; Science 2011, 334, 780.

16. Hazari, N.; Chem. Soc. Rev. 2010, 39, 4044.

17. Danopoulos, A. A.; Wright, J. A.; Motherwell, W. B.; Chem. Commun. 2005, 784.

18. Creutz, S. E.; Peters, J. C.; J. Am. Chem. Soc. 2014, 136, 1105.

19. Anderson, J. S.; Rittle, J.; Peters, J. C.; Nature 2013, 501, 84.

20. Mondragón, A.; Flores-Alamo, M.; Martínez-Alanis, P. R.; Aullón, G.; Ugalde-Saldívar, V. M.; Castillo, I.; Inorg. Chem. 2015, 54, 619.

21. CrysAlis ${ }^{P R O}$ and CrysAlis ${ }^{R E D}$, Agilent Technologies, Yarnton, England, 2013.

22. Clark, R. C.; Reid, J. S.; Acta Crystallogr. 1995, A51, 887.

23. Sheldrick, G. M.; Acta Crystallogr. 2015, A71, 3.

24. Sheldrick, G. M.; Acta Crystallogr. 2015, C71, 3.

25. Farrugia, L. J.; J. Appl. Crystallogr. 1999, 32, 837.

26. Flores-Figueroa, A.; Arista-M., V.; Talancón-Sánchez, D.; Castillo, I.; J. Braz. Chem. Soc. 2005, 16, 397.

27. Huerta, R.; Castillo, I.; Hernández-Ortega, S.; Acta Crystallogr. 2008, E64, o323.

28. Wang, H. M. J.; Lin, I. J. B.; Organometallics 1998, 17, 972.

29. Lin, I. J. B.; Vasam, C. S.; Coord. Chem. Rev. 2007, 251, 642.

Submitted: December 18, 2017

Published online: March 15, 2018 